\title{
Can a Greenhouse Be Established
}

\author{
on Mars?
}

\author{
Danielle Schlehahn*, Alyssa Boudreau, Braden Barber, Braden \\ Kowalchuk, Brette Langman, \& Jason Worobec
}

\begin{abstract}
This study investigates the potential of establishing a greenhouse on Mars. In order to sustain a greenhouse on Mars, the variables that must be considered are water, soil, atmosphere, light, temperature, design, and plants. Water is present on Mars in the form of ice in frozen soil. Water extraction can be achieved by heating, microwaves, or humidifier type devices. The water that is extracted is highly salty. However, ion exchange, reverse osmosis, or biological treatments can be used to treat the water. By using an underground irrigation system, this water can be applied directly to plant roots. Soil is readily available on Mars, and, with the exception of reactive nitrogen, this soil contains the nutrients required for plant growth. Nitrogen fixers, such as Cyanobacteria, can convert nitrogen from the atmosphere into reactive nitrogen. This reactive nitrogen can be directly applied to the plants. The atmosphere of Mars contains 95.32\% Carbon Dioxide, $2.7 \%$ Nitrogen, $1.6 \%$ Argon, $0.13 \%$ Oxygen and $0.08 \%$ Carbon Monoxide. Mars' atmosphere is very thin so it has difficulty capturing solar energy, but this difficulty can be overcome by creating more greenhouse gases on the planet via thawing the poles using orbital mirrors, creating greenhouse gas factories, or smashing ammonia heavy asteroids into the planet. Artificial light can also be used to supply solar energy. Temperatures on Mars fluctuate between 35 to - 90 degrees Celsius, depending on the season. To overcome these large fluctuations, a radioisotope heater can be used to maintain temperatures within the greenhouse between the ideal 0 - 40 degrees Celsius. Robots or humans can set up and maintain the greenhouse. Plants that are to be grown in a greenhouse on Mars must be able to sustain human life by providing the proper nutrients. These include soybeans, spinach, mushrooms, wheat, Spirulina platensis (cyanobacteria supplementation) and seaweed. Ultimately, this research suggests that building and maintaining a Martian greenhouse may be feasible in the future by utilizing a number of techniques and technologies.
\end{abstract}

Keywords: greenhouse, Mars, agriculture

\section{Introduction}

Earth's population is growing at a rapid pace, to the point where it becomes concerning that the carrying capacity has been overcome. Scientists project that we will need to double our food production by 2050, ${ }^{1}$ which will be challenging due to the ever-growing population overtaking valuable farmland. We are overusing nonrenewable resources such as minerals, fossil fuels, and water and the growing population is also causing an increase in greenhouse gas emissions, which are affecting the atmosphere negatively by increasing Earth's atmospheric temperature. Because of these problems, it has become

*Department of Physics, College of Arts and Science, University of Saskatchewan, Saskatoon, SK, Canada

+Correspondence: drs.578@mail.usask.ca 
important to look into other planets that could potentially sustain life.

Mars has strong potential to eventually support human life because of its close proximity to the Sun and its atmospheric composition. One critical factor to assess is the potential to support and sustain plant growth on Mars. This would be achieved by setting up a greenhouse that can manipulate Mars' atmosphere to mimic Earth's. This paper will summarize current science-based understandings of the conditions on Mars and explain what is required to grow plants in a greenhouse. These conditions include the water, soil, temperature, light and atmospheric composition of Mars. The plants that should be grown and how the greenhouse will be transported to Mars will also be discussed. When humans do succeed in growing plants on Mars, this will mean that we are one step closer to sustaining the growing human population.

\section{Water On Mars}

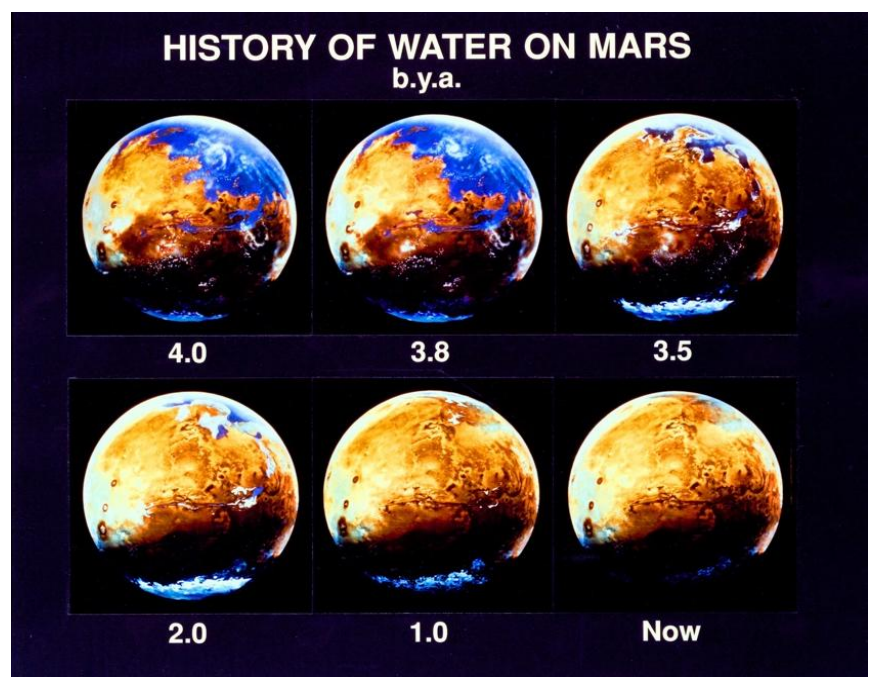

Figure 1 - The history of water on Mars and how it varies over time.

Source: https://archive.org/details/AILS_AC90-0559-1 Credited to: NASA/Ames Research Center

Water availability on a planet is a key component to grow plants and ultimately sustain a human population. Fortunately, in 2015, NASA's Mars Reconnaissance Orbiter (MRO) found the most concrete evidence to date that liquid water flows intermittently on present-day Mars. ${ }^{2}$ However, the water may be briny, which causes a lower freezing point. $^{2}$ These hydrated salts likely consist of magnesium perchlorate, magnesium chlorate, and sodium perchlorate. ${ }^{2}$

This brings into question where this water is located and where it came from. Recently, researchers found that there is a giant slab of ice underneath Mars's surface, which could be due to a snowfall that occurred tens of millions of years ago. ${ }^{3}$ Interestingly, the amount of water on Mars has been altered immensely due to Mars's unstable obliquity, $^{2}$ which can be seen in Figure 1 . Mars' obliquity is described as "the degree to which the planet tilts on its axis of rotation." ${ }^{3}$ The difference between Earth and Mars, in this respect, is that Mars's moons do not prevent this wobble. ${ }^{3}$ This unpredictable wobble results in regular ice ages on Mars. ${ }^{3}$

Mars has a northern and southern icecap that are composed almost entirely of water ice, despite being previously believed to be mainly dry ice. ${ }^{4}$ This was discovered using high-resolution and thermal images from Mars Global Surveyor and Mars Odyssey, respectively. ${ }^{4}$ The images gathered were of flat-floored circular pits that were $8 \mathrm{~m}$ and $200 \mathrm{~m}$ to $1000 \mathrm{~m}$ across at the south polar cap of Mars. ${ }^{4}$ These caps grow outwards by 1 to $3 \mathrm{~m}$ every year. ${ }^{4}$ Mars Odyssey produced pictures that show the lower material heats up, similar to how water ice would in a Martian summer, which suggests these caps are

composed of water and not dry ice. ${ }^{4}$ Apparently, both the south and north poles have a thin covering of dry ice, with the inner and bottom layers composed of water ice. ${ }^{4}$ The north pole's layer of dry ice is thinner ( $1 \mathrm{~m})$ and melts in the summertime, whereas the south pole's $8 \mathrm{~m}$ thick layer does not melt entirely. ${ }^{4}$

The data gathered clearly suggests the presence of water on Mars, but it becomes important to understand how this water will be extracted and treated so that it can possibly be utilized for plant and human sustenance. NASA's Curiosity rover found that water molecules were present in soil samples analyzed by its Sample Analysis at Mars (SAM) instruments. ${ }^{5}$ This suggests that Martian soil potentially contains about two pints of water per cubic foot of soil. ${ }^{5}$

A number of different methods have been suggested for harvesting Martian water.. The obvious method of retrieving this water from the soil is to dig up frozen soil and bake in an oven until the water evaporates. ${ }^{5}$ In addition to this method, a microwave beam could be used to heat up rock, which heats up the ice that can be condensed into drinkable water. ${ }^{5}$ In another design, an oven-like device can be used to extract water on Mars so it is drinkable. ${ }^{6}$ Water can also be extracted from the atmosphere using a humidifier type device, ${ }^{7}$ but it is suggested that the best method is to mine ice from the polar caps or from beneath the soil and melt it. ${ }^{7}$ This is because the liquid water is transient, meaning that it is only there during the warm season. ${ }^{7}$ This would not be a reliable source of water, however. The water is widespread, so there is a lack of volume in any one area.

Before this water is drinkable it needs to go through a process of desalination. Perchlorates cause thyroid problems and negatively affect the gastrointestinal tract, skin, breast tissue and placentas. ${ }^{7}$ Three methods of desalination include ion exchange, reverse osmosis and 
biological treatment. ${ }^{7}$ Ion exchange involves swapping perchlorate ions out for other molecules of similar charge. ${ }^{7}$ Reverse osmosis uses pressure to push liquid through a membrane with small holes only big enough for water to go through. ${ }^{7}$ Lastly, biological treatment utilizes bacteria to eat perchlorate, ${ }^{7}$ which has the advantage of not requiring maintenance in treating the waste.

Once the water is collected and treated, it must be applied to the plants. This can be accomplished by using underground irrigation systems similar to ones used on earth that apply water directly to roots. ${ }^{8}$

\section{Soil Composition/How We Could Change It}

Unlike water, there is a bountiful supply of readily available soil on Mars. Luckily, Martian soil already contains most of the nutrients required for plant growth, with the exception of reactive nitrogen, which is a necessary nutrient to the growth of plants. ${ }^{9}$ The nitrogen atoms that are currently present on Mars need to be "fixed" or separated, so that they are then able to become "reactive." Without being fixed, it will remain as nitrogen gas and will not become reactive, which will not allow full, successful plant growth. ${ }^{10}$ A nitrogen "fixer" such as Cyanobacteria utlizes an enzyme that gathers nitrogen gas and converts it into a reactive nitrogen. ${ }^{11}$ Martian soil holds water very well, which in turn benefits the performance of plant growth because the soil will not easily dry out. ${ }^{9}$ Martian soil has also been found to contain nutrients such as sodium, potassium, and magnesium, amongst other things. ${ }^{12}$

\section{Atmosphere}

\begin{tabular}{|l|l|}
\hline \multicolumn{1}{|c|}{ Mars (\%) } & \multicolumn{1}{|c|}{ Earth (\%) } \\
\hline Carbon dioxide: 95.32 & Nitrogen: 78.0 \\
Nitrogen: 2.7 & Oxygen: 21.0 \\
Argon: 1.6 & Argon: 0.93 \\
Oxygen: 0.13 & Carbon dioxide: 0.038 \\
Carbon monoxide: 0.08 & \\
\hline
\end{tabular}

Table 1 - The atmospheric composition of Mars (left) and Earth (right).

The atmospheric composition of Mars vastly differs from the life sustaining atmosphere of Earth, which can be seen in Table 1. Despite these differences, Mars has the potential to sustain plant life on the planet due to the high concentration of carbon dioxide, as it is essential for photosynthesis. The process of photosynthesis requires water and solar energy. In the case of Mars, both are not very abundant. Mars's atmosphere is one hundred times thinner than Earth's; therefore, it is difficult to capture solar energy. ${ }^{13}$ The atmosphere can be made denser using a few different techniques, such as thawing the north and south poles using orbital mirrors, creating greenhouse gas factories to create more gases, or smashing ammonia heavy asteroids into the planet. ${ }^{13}$ These techniques will create an increase in greenhouse gas which would effectively trap solar energy and reflect it back onto the planet surface. Another disadvantage is that Mars' decreased gravity creates an atmosphere that extends four kilometers further than Earth's. ${ }^{15}$ The low gravity means more gases must be created to induce an effect. Lack of water and gravity are also factors that can be manipulated within the greenhouse to obtain desirable conditions for plants to grow.

\section{Temperature}

In addition to these factors laid out above, the ambient temperature is another key aspect to the success of growing plants on Mars. Two rovers sent to Mars, Spirit and Opportunity, have played a key role in determining the temperature on Mars, which is illustrated in Figures 2 and $3 .{ }^{16}$ Between both Rovers, it was found that there was an average of 30-35 degrees Celsius during the summer months on Mars. ${ }^{16}$ During the winter months there was an average of negative 90-80 degrees Celsius with a low of negative 110 degrees Celsius. ${ }^{16}$ Spirit was further from the equator than Opportunity and therefore there was variance in temperature, which is illustrated in the second figure. ${ }^{16}$ One of the theories on why the temperature varies on Mars more than Earth is due to it having a very thin atmosphere. ${ }^{17,18}$ In fact, its atmosphere is one hundred times thinner than Earth's which hinders its ability to create a "thermal blanket" to trap solar heat. ${ }^{18}$

Consequently, this extreme temperature range will have to be mitigated in order to sustain plant life on Mars. To overcome this obstacle, a multi-mission radioisotope thermoelectric generator (MMRTG) could be used. This novel technology uses a nuclear battery that can convert heat into electricity. ${ }^{19}$ This system is able to be used during the colder winter months and has been tested as a reliable radioisotope heater. ${ }^{19}$ Physiological processes in plants do the best in temperatures from $0-40$ degrees Celsius ${ }^{20}$ therefore, a thermostat will have to be implemented to ensure that the heater will turn on when the temperature is below o degrees Celsius and turn off when the temperature is above 40 degrees Celsius. 


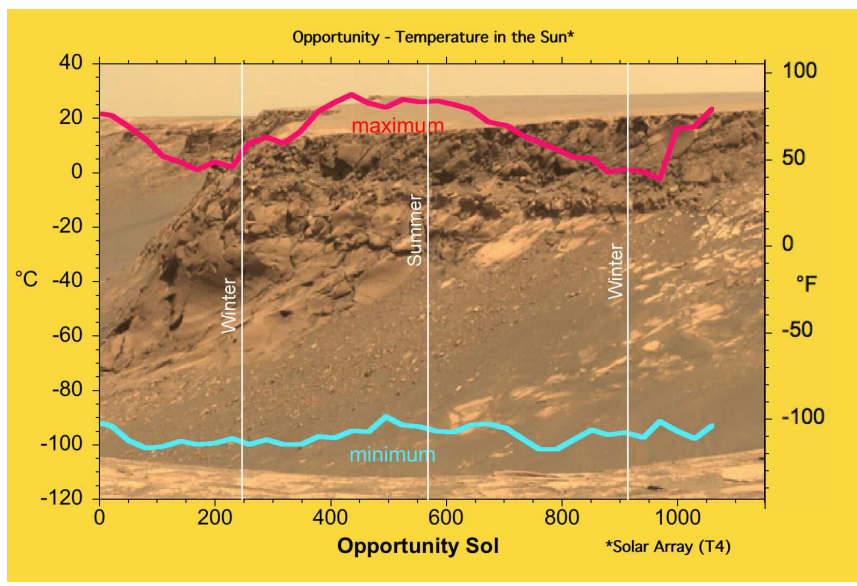

Figure 2 - Source: http://mars.nasa.gov/mer/spotlight/ 20070612.html. Credited to: NASA

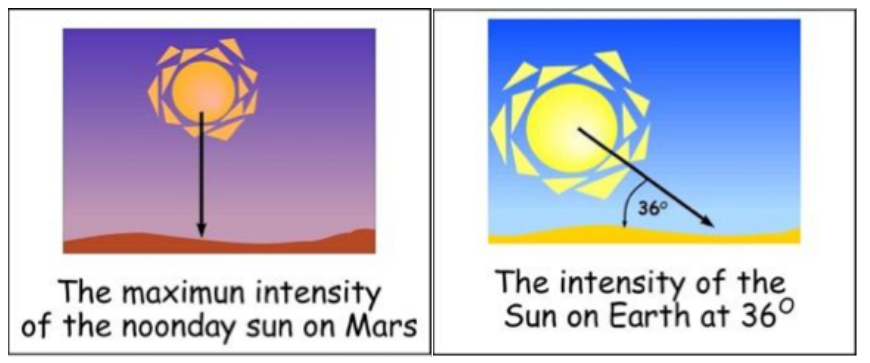

Figure 4 - The maximum intensity of the Sun at noon on Mars is equal to the intensity of the Sun on Earth when it is 36 degrees above the horizon.

Source: http://resources.yesican-

science.ca/tomatosphere/final/trans_irradiance2.html

\section{Light}

It is no surprise that in order to successfully grow plants in any location, sufficient light is required. Mars is further away from the Sun and as a result receives close to half the sunlight Earth does. ${ }^{21}$ Figures 4 and 5 show how the intensity of light differs on Mars compared to Earth.

Figure 4 shows that the maximum intensity of sunlight on Mars during high noon is about equal to the intensity of light on Earth when the sun is only 36 degrees above the horizon. $^{22}$ Figure 5 shows the Sun's spectra on Earth compared to Mars. Although the shape of each graph is the same they differ in height. ${ }^{22}$ Additionally, the area of each spectra is proportional to the energy of the sunlight. ${ }^{22}$ This poses a problem for growing plants using Mars' sunlight. The low amount of solar energy reaching Mars will restrict a plant's rate of photosynthesis and reduce the plant's growth, development, and yield. ${ }^{23}$ For the best yield of Martian crops food production will have to be grown in a greenhouse supplemented by artificial lighting.

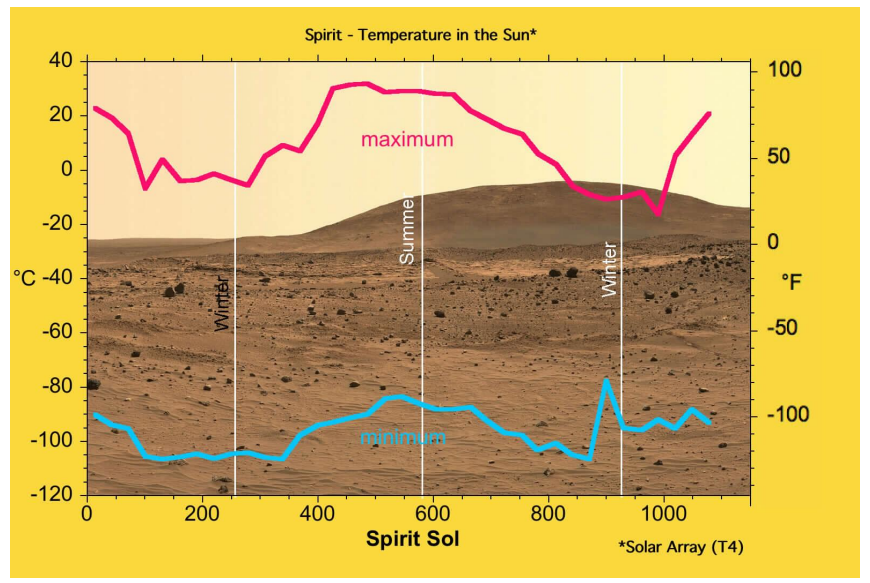

Figure 3 - Source: http://mars.nasa.gov/mer/spotlight/ 20070612.html. Credited to: NASA
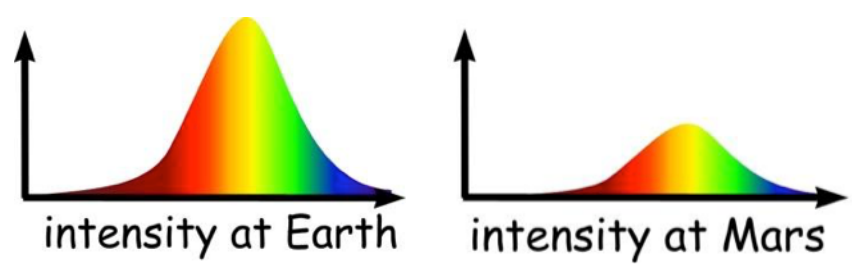

Figure 5 - Spectra of Sun's light on Earth compared to Mars. Source: http://resources.yesicanscience.ca/tomatosphere/final/trans_mars_sun.html

Today artificial lighting for the purpose of plant production is better and more efficient than it has ever been. Research has shown that light-emitting diodes or LED's are very successful in aiding plant production. ${ }^{24}$ LED lights are small, durable, and they last a long time. ${ }^{24}$ They can be placed closer to the plant material because they don't get as hot as traditional lighting and they emit specific wavelengths that can be manipulated to cater to specific plant needs and stages in the plant's development. ${ }^{24}$ These lights could potentially run off solar panels in good conditions but backup power will be necessary. Using LED's in a greenhouse environment on Mars will be essential to the success of food production.

There are also dangerous amounts of solar radiation that reaches the surface of Mars. Because Mars has a thinner atmosphere solar radiation such as ultraviolet light can reach the surface and cause damage to any form of biological life making it impossible to grow plants when in direct exposure. ${ }^{25} \mathrm{~A}$ greenhouse will need to be built with a material that allows visual light through, blocks UV 
radiation and $\mathrm{X}$-Rays, and traps infrared radiation. Researchers have suggested creating an igloo like structure by harvesting ice from the Martian surface and melting it down to be $3^{D}$ printed by robots into a building made of ice as shown in Figure $6 .{ }^{26}$ They say that ice would be a perfect material for a safe structure on Mars because it can be made from sources already found on the planet and it acts as a shield against harmful radiation but allows visual light in. $^{26}$

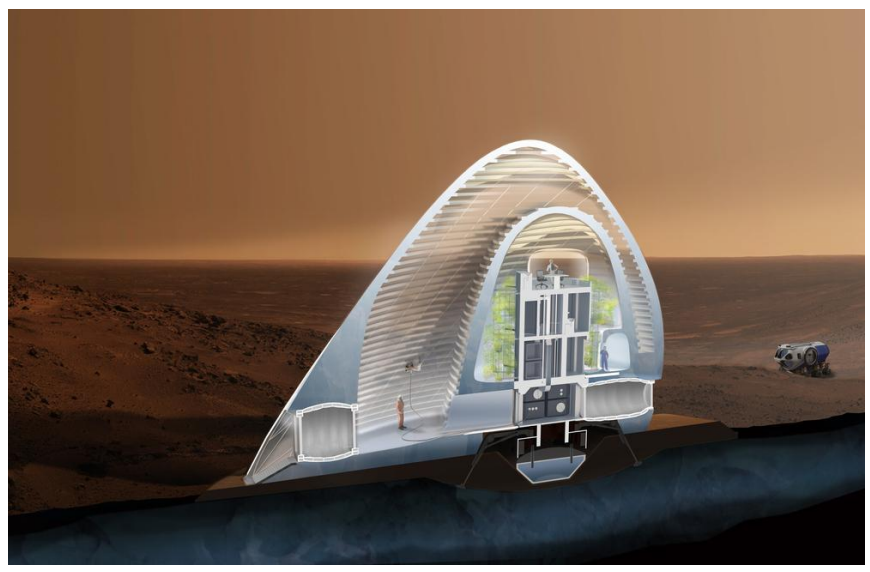

Figure 6 - 3D printed ice Greenhouse and Habitat. Source: http://www.marsicehouse.com/habitat/bd2dg1r mtu736qy2wc9jbjpgozr4oe

\section{Greenhouse Attributes}

In order to achieve the goal of growing plants on Mars, a greenhouse will have to be implemented in order to combat the unfavorable conditions mentioned above. As described above, the main conditions that will need to be altered are the water, atmosphere, temperature and lighting. The water will need to be harvested and desalinated before it can be used in the greenhouse. The atmosphere within the greenhouse can be manipulated by carbon dioxide generators and irrigation systems. A multi-mission radioisotope thermoelectric generator (MMRTG) could be used to maintain the temperature in the greenhouse. This uses a nuclear battery that can convert heat into electricity. A thermostat will need to be installed in the greenhouse to maintain the ambient temperature at a range of $0-40$ degrees Celsius. The thermostat will ideally ensure that the MMRTG will turn on when the temperature is below 0 degrees Celsius and turn off when the temperature is above 40 degrees Celsius. As for lighting, the greenhouse will have to have be equipped with LED lighting for the plants to have optimal growth.

\section{Installation and Maintenance of Greenhouse}

The greenhouse will have to be properly installed before it can be functional. Pre-programmed robots could potentially be used to set up, run, and maintain the greenhouse. They would be sent to Mars with the plants and the greenhouse building supplies, and be controlled from Earth. Astronauts could also travel to Mars, set the greenhouse up, and maintain it. Even though robots seem more convenient, it is important to remember that it may not be possible to properly train the robot "staff" to adapt to every potential situation that may come up. Astronauts would be able to adapt to situations without question or direction. Additionally, if they are already there, the travel time of the astronauts will not have to be factored in to mediate a problem. Ultimately, humans will be responsible for the installation and maintenance of plants. This will allow for the planting, harvesting, replanting, and any other maintenance that arises.

In terms of the material that will be used for the greenhouse, it would be beneficial to have something light weight, such as fiberglass. Although this would take up a lot of space, it would save fuel costs because of the lack of mass. Metal and glass would be very heavy, which would in turn use up more fuel and raise costs. Interestingly, a former astronaut, John Grunsfeld, stated that it would be possible to have an inflatable greenhouse that would be set up when the crew arrived on Mars. ${ }^{27}$ This would be even lighter than fiberglass and take up much less room. The main downfall, however, is that it may not be as durable as fibreglass, so it would not be a long-term option. Figure 7 shows a potential greenhouse set up on Mars.

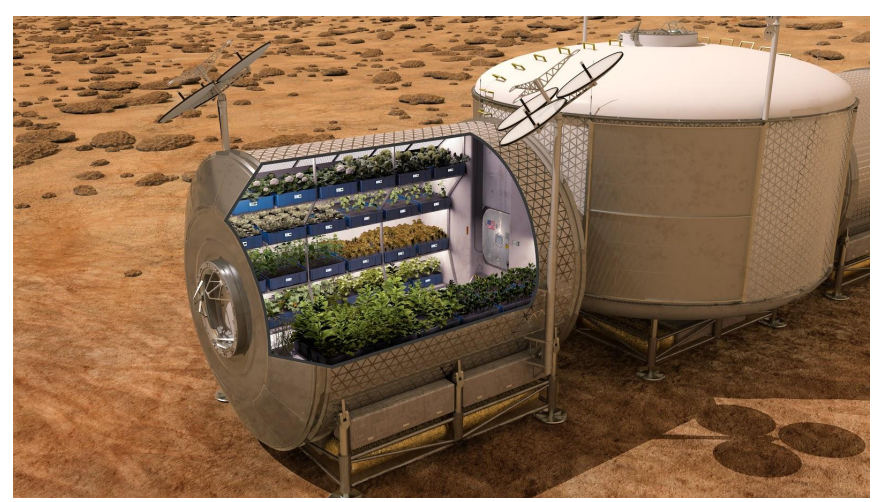

Figure 7 - Potential greenhouse build/setup on Mars Source: http://www.nasa.gov/mission_pages/station/ research/news/meals_ready_to_eat. Image Credit: NASA. 


\section{Plants to Be Grown}

The main purpose of this expedition is to investigate the possibility of providing a source of nutrition for future colonists on Mars. In order for the colonists to be nutritionally self-sufficient, they will need plants that provide the nutrition needed for the human body. Therefore, the colonists need more than cabbage and potatoes to sustain life. It is important to understand what the basic nutrition needed to sustain human life is. Table 2 shows the daily reference values and the reference daily intakes for adults and children four or more years of age, as recommended by the U.S. Food and Drug Administration (FDA). ${ }^{28}$ This table is particularly useful, because it shows the advanced nutritional requirements for human life. Other food guides, such as Health Canada's Food Guide, only provide basic nutritional recommendations. Different foods provide different nutrients. For example, only growing and eating potatoes would lead to many nutrient deficiencies. This is because potatoes are not a source of vitamins $B 12, A$ and $D$; potatoes are also a very poor source of protein, lipids, vitamin $E$ and $K$, sodium and magnesium. ${ }^{29}$ The plants that have been chosen for this project were chosen because they provide excellent nutrition to meet the human requirements. Another reason for choosing them, is that the nutrition that they provide is in very concentrated amounts. Thus, a relatively small area of land can produce adequate nutrition for humans.

Given the values in Table 2, the plants that will be grown on Mars in order to achieve these requirements must be determined. The organisms that will be grown in order to meet the FDA recommendations are: soybeans, spinach, mushrooms, wheat, Spirulina platensis (cyanobacteria supplementation) and seaweed (Canadian Cultivated EMITSUNOMATA). This may not appear to be the tastiest selection of plants; however, it is a diet that should sustain human life according to the research shown in Table 3 (see page 7). Table 3 shows the FDA nutrition references, ${ }^{27}$ and the included plants' nutrition, to prove they meet nutritional requirements to justify their inclusion. Ultimately, successful growth of these plants will be an adequate start to the validation that Mars can support humans in the future.

\begin{tabular}{|c|c|}
\hline Food Component & DV \\
\hline Total Fat & 05 grams (g) \\
\hline Saturated Fat & $20 \mathrm{~g}$ \\
\hline Cholesterol & 300 millorams ( $m$ q) \\
\hline Sodium & $2,400 \mathrm{mg}$ \\
\hline Potassium & $3,500 \mathrm{mg}$ \\
\hline Total Carbohydrate & 300 \\
\hline Dietary Fiber & 258 \\
\hline Protein & $30 \mathrm{~g}$ \\
\hline Vtamin A & 5.000 International Units (IU) \\
\hline Vtamin C & $60 \mathrm{mg}$ \\
\hline Calcium & $1,000 \mathrm{mg}$ \\
\hline Iron & $18 \mathrm{mg}$ \\
\hline Vtamin D & $400 \mathrm{IU}$ \\
\hline Veamin E & $30 \mathrm{IU}$ \\
\hline Veamin $\mathrm{K}$ & 80 micrograms vg \\
\hline Thiamin & $1.5 \mathrm{mg}$ \\
\hline Ribollavin & $1.7 \mathrm{mg}$ \\
\hline Nacin & $20 \mathrm{mg}$ \\
\hline Vtamin BB & $2 \mathrm{mg}$ \\
\hline Folate & 400 pg \\
\hline Veamin B12 & $6 \nu$ \\
\hline Biotin & 300 vo \\
\hline Pantothenic acid & $10 \mathrm{mg}$ \\
\hline Phosphorus & $1,000 \mathrm{mg}$ \\
\hline lodine & $150 \mu g$ \\
\hline Magnesium & $400 \mathrm{mg}$ \\
\hline Zine & $15 \mathrm{mg}$ \\
\hline Selenium & $70 \mathrm{No}$ \\
\hline Copper & $2 \mathrm{mg}$ \\
\hline Manganese & $2 \mathrm{mg}$ \\
\hline Chromium & $120 \mathrm{Ng}$ \\
\hline Molybdenum & $75 \mu$ \\
\hline Chioride & $3,400 \mathrm{mg}$ \\
\hline
\end{tabular}

Table 2 - The daily reference values and the reference daily intakes of a $2000 \mathrm{kcal}$ diet for adults and children four or more years of age. Values are given by the U.S. Food and Drug Administration. ${ }^{28}$ 


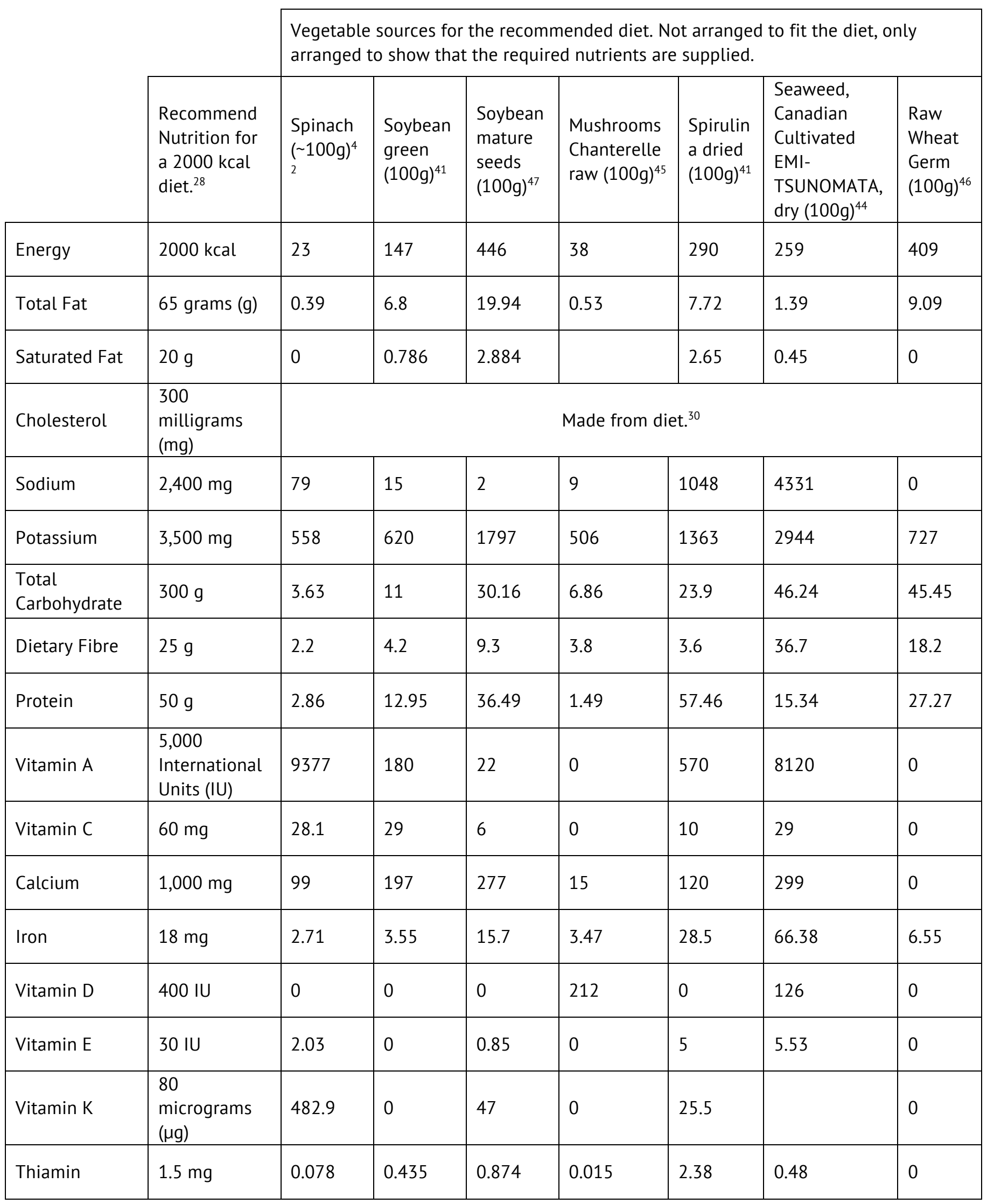




\begin{tabular}{|c|c|c|c|c|c|c|c|c|}
\hline Riboflavin & $1.7 \mathrm{mg}$ & 0.189 & 0.175 & 0.87 & 0.215 & 3.67 & 1.59 & \\
\hline Niacin & $20 \mathrm{mg}$ & 0.724 & 1.65 & 1.623 & 4.085 & 12.82 & 3.75 & \\
\hline Vitamin B6 & $2 \mathrm{mg}$ & 0.195 & 0.065 & 0.377 & 0.044 & 0.364 & 0.23 & \\
\hline Folate & $400 \mu \mathrm{g}$ & 194 & 165 & 375 & 2 & 94 & 188 & \\
\hline Vitamin B12 & $6 \mu \mathrm{g}$ & 0 & 0 & 0 & 0 & $\mathrm{See}^{*}$ & 2.25 & \\
\hline Biotin & $300 \mu \mathrm{g}$ & \multicolumn{7}{|c|}{ Information not given to scale. Is present in diet from wheat. ${ }^{38}$} \\
\hline $\begin{array}{l}\text { Pantothenic } \\
\text { acid }\end{array}$ & $10 \mathrm{mg}$ & \multicolumn{7}{|c|}{ Information not given to scale. Is present in diet from wheat. ${ }^{38}$} \\
\hline Phosphorus & $1,000 \mathrm{mg}$ & 49 & 194 & 704 & 506 & 0 & 0 & \\
\hline lodine & $150 \mu \mathrm{g}$ & & & & & & & \\
\hline Magnesium & $400 \mathrm{mg}$ & 79 & 65 & 280 & 13 & 195 & 0 & \\
\hline Zinc & $15 \mathrm{mg}$ & 0.53 & 0.99 & 4.89 & 0.71 & 2 & 0 & \\
\hline Selenium & $70 \mu \mathrm{g}$ & \multicolumn{6}{|c|}{ Information not given to scale. Is present in diet from spinach. ${ }^{32}$} & \\
\hline Copper & $2 \mathrm{mg}$ & \multicolumn{6}{|c|}{ Information not given to scale. Is present in diet from soybeans. ${ }^{33}$} & \\
\hline Manganese & $2 \mathrm{mg}$ & \multicolumn{6}{|c|}{ Information not given to scale. Is present in diet from spinach. ${ }^{34}$} & \\
\hline Chromium & $120 \mu \mathrm{g}$ & \multicolumn{6}{|c|}{ Information not given to scale. Is present in diet from wheat. ${ }^{35}$} & \\
\hline Molybdenum & $75 \mu \mathrm{g}$ & \multicolumn{6}{|c|}{ Information not given to scale. Is present in diet from soybeans. ${ }^{36}$} & \\
\hline Chloride & $3,400 \mathrm{mg}$ & \multicolumn{6}{|c|}{ Information not given to scale. Is present in diet from seaweed. ${ }^{38}$} & \\
\hline
\end{tabular}

* perhaps with bioengineering we could make the unavailable B12 available for humans. ${ }^{40}$

Table 3 - Table detailing how the diet proposed in this research meets the FDA references for nutrition. Where information is not given to scale, the requirements are minimal. Thus, as long as the nutrient is present in diet, it will meet the respective requirement. 


\section{Conclusion}

It is clear that this mission is only possible if we are able to harmoniously integrate a variety of human science and understanding. Agriculture is a driving force for the relatively recent development of the human race and the success of this experiment will ensure further development of the human population. To develop Martian agriculture, a greenhouse requires an artificial, Earth-like environment that can only be achieved and sustained when we understand the environment in which it will exist. Growing plants on an entirely different planet will be a true test. According to this research, there must be a reliable source of water and it is questionable if the water on Mars will be suitable or even accessible for plant consumption. Soil is readily available but requires modification to provide all necessary nutrients. The atmosphere is rich in carbon dioxide, but is too thin to provide sustainable temperatures for plants or to block out harmful UV and $X$-rays. Sunlight will need to be subsidized to provide proficient plant yields. A greenhouse can easily imitate necessary atmospheric conditions for plants but only if suitable soil and water can be sourced. It is best to send this greenhouse to Mars and have it be set up autonomously but this provides its own set of challenges. It could be difficult to program robots to grow plants or problem solve when issues arise. A human element can provide much more success but is risky and expensive during initial settlement stages. Yet, a mission such as this is imperative to human exploration in space. If plants can be successfully grown on Mars, there is a higher chance of sustaining human life and growth in the future, as well as extending our reach further into our solar system.

\section{References}

1. United Nations, Food Production Must Double by 2050 to Meet Demand from World's Growing Population, Innovative Strategies Needed to Combat Hunger, Experts Tell Second Committee, WWW document, Acessed on November 4, 2016 (http://www.un.org/press/en/2009/gaef3242.doc.htm)

2. D. Brown, L. Cantillo and G. Webster, NASA Confirms Evidence That Liquid Water Flows on Today's Mars, WWW document, Accessed on October 7, 2016, (https://www.nasa.gov/press-release/nasa-confirmsevidence-that-liquid-water-flows-on-today-s-mars)

3. C. Q. Choi, Gigantic Ice Slab Found on Mars Just Below the Planet's Surface, WWW document, Accessed on October 7, 2016, (http://www.space.com/30502-marsgiant-ice-sheet-discovery-mro.html)

\section{R. Tindol, The Martian Polar Caps Are Almost Entirely} Water Ice, Caltech Research Shows, WWW document, Accessed on October 7, 2016, (https://www.caltech.edu/news/martian-polar-caps-arealmost-entirelywater-ice-caltech-research-shows-660)

5. T. Lewis, Incredible Technology: How to Mine Water on Mars, WWW document, Accessed on October 7, 2016, (http://www.space.com/24052-incredible-tech-miningmars-water.html)

6. J. Wiens et al., Water Extraction from Martian Soil, WWW document, Accessed on October 7, 2016, (http://www.lpi.usra.edu/publications/reports/CB1106/csm01.pdf)

7. D. Hernandez, What It Would Take to Drink the Water on Mars, WWW document, Accessed on October 7, 2016, (http://fusion.net/story/205189/water-mars-futurehuman-habitats/)

8. Hunter Industries, Root Zone Watering System, WWW document, Accessed on October 7, 2016.

(http://www.hunterindustries.com/irrigationproduct/micro-irrigation/root-zone-watering-system).

9. Wamelink, G. W. Wieger et al, Can Plants Grow On Mars And The Moon: A Growth Experiment On Mars And Moon Soil Simulants, WWW document, Accessed on October 9 , 2016, (https://www.ncbi.nlm.nih.gov/pmc/articles/PMC4146463 /\#pone.0103138-Stevens1)

10. N. Neal-Jones and W. Steigerwald, NASA's Curiosity Rover Finds Biologically Useful Nitrogen on Mars, WWW document, Accessed on October 9, 2016, (http://www.nasa.gov/content/goddard/mars-nitrogen)

11. M. Stone, The Key to Colonizing Mars Could Be These Tiny Green Microbes, WWW document, Accessed on 
October 9, 2016, (http://gizmodo.com/the-key-tocolonizing-mars-could-be-these-tiny-green-mi1731268670)

12. BBC News,Martian soil 'could support life', WWW document, Accessed on November 14, 2016, (http://news.bbc.co.uk/2/hi/science/nature/7477310.stm) 13. T. Sharp, Mars Atmosphere: Composition, Climate \& Weather, WWW document, Accessed on October 11, 2016, (http://www.space.com/16903-mars-atmosphere-climateweather.html)

14. T. Sharp, Earth's atmosphere: Composition, Climate and Weather, WWW Document, Accessed on November 6, 2016, http://www.space.com/17683-earthatmosphere.html

15. J. Coffey, (2015), Atmosphere of Mars, WWW Document, Accessed on September 24, 2016, http://www.universetoday.com/22587/atmosphere-ofmars/

16. Extreme Planet Takes Its Toll, WWW document, Accessed on October 12, 2016, (http://mars.nasa.gov/mer/spotlight/20070612.html)

17. T. Sharp (2012), What is the temperature on Mars, WWW document (http://www.space.com/16907-what-isthe-temperature-of-mars.html)

18. T. Sharp, Mars Atmosphere: Composition, Climate \& Weather, WWW document, accessed on October 11, 2016, (http://www.space.com/16903-mars-atmosphere-climateweather.html)

19. NASA facts. Multi-Mission Radioisotope

Thermoelectric Generator (MMRTG). National Aeronautics and Space Administration. WWW document, Accessed on November 15, 2016,

(http://mars.nasa.gov/mars2020/files/mep/MMRTG_FactS heet_update_10-2-13.pdf)

20. F.W. Went, (1953), The effect of temperature on plant growth, 4: 347-362, WWW document, Accessed on

October 12, 2016,

(http://www.annualreviews.org/doi/abs/10.1146/annurev. pp.04.060153.002023?journalCode=arplant.1)

21. Moskowitz, C. (2013), Farming on Mars: NASA Ponders Food Supply for 2030s Mission, Accessed on October 11,
2016, http://www.space.com/21028-mars-farming-nasamissions.html.

22. Tomatosphere (n.d.), Is There Enough Light On Mars To Grow Tomatoes, Accessed on October 11, 2016, http://resources.yesican-

science.ca/tomatosphere/final/mars_agri.html

23. Bareja, B.G. (2011), What is Light Intensity, Effects on Plant Growth, Accessed on November 9, 2016, http://www.cropsreview.com/light-intensity.html

24. Massa, G.D. (2008), Hortscience: Plant Productivity in Response to LED Lighting, 43 (7), Accessed on November 9, 2016, http://hortsci.ashspublications.org/content/43/7/1951.ful l

25. Patel, M.R., Berces, A., Kerekgyarto, T., Ronto, G., Lammer, H., Zarnecki, J.C. (2004). Annual Solar UV Exposure and Biological Effective Dose Rates on the Martian Surface. Advances in Space Research, 33 (8), Accessed on October 11, 2016, http://dx.doi.org/10.1016/j.asr.2003.08.036.

26. S. Larson, Humans could inhabit Mars with the help of this 3D-printed ice house, The Daily Dot. Accessed on November 29, 2016, http://www.dailydot.com/debug/mars-ice-house-nasa/

27. R. Stella, Nasa says a simple greenhouse will allow Astronauts to grow food on Mars, WWW document, Accessed on October 9, 2016, (http://www.digitaltrends.com/cool-tech/nasa-says-itsnow-possible-to-build-greenhouses-on-mars/)

28. U.S. Food and Drug Administration, Guidance for Industry: A Food Labeling Guide (14. Appendix F:

Calculate the Percent Daily Value for the Appropriate Nutrients), WWW Document, Accessed on October 11, 2016, (http://www.fda.gov/Food/GuidanceRegulation/Guidance DocumentsRegulatoryInformation/LabelingNutrition/ucm 064928.htm) 
29. United States Department of Agriculture Agricultural Research Service, 11352, Potatoes, flesh and skin, raw WWW Document, Accessed on November 9, 2016, (https://ndb.nal.usda.gov/ndb/foods/show/80768?fgcd=\& manu $=\&$ lfacet $=\&$ format $=\&$ count $=\& \max =50 \&$ offset $=\&$ sor $\mathrm{t}=$ default \&order=asc \&qlookup=romaine+lettuce \&ds)

30. American Heart Association, About Cholesterol, WWW Document, Accessed on October 11, 2016, (http://www.heart.org/HEARTORG/Conditions/Cholesterol /AboutCholesterol/About-

Cholesterol_UCM_001220_Article.jsp\#.WAFBqegrKM9)

31. Dr. Edward Group, 7 Foods Rich in lodine, WWW Document, Accessed on October 11, 2016, (http://www.globalhealingcenter.com/naturalhealth/iodine-foods/)

32. Dr. Edward Group, The 7 Best Vegetarian Foods for Selenium, WWW Document, Accessed on October 11, 2016, (http://www.globalhealingcenter.com/naturalhealth/best-vegetarian-foods-selenium/)

33. The World's Healthiest Foods, Copper, WWW Document, Accessed on October 11, 2016, (http://www.whfoods.com/genpage.php?tname=nutrient \&dbid=53)

34. Oregon State University, Maganese, WWW Document, (http://lpi.oregonstate.edu/mic/minerals/manganese)

35. U.S. Department of Health and Human Services, Chromium, WWW Document, Accessed on October 11, 2016, (https://ods.od.nih.gov/factsheets/ChromiumHealthProfessional/)

36. The World's Healthiest Foods, Molybdenum, WWW Document, Accessed on October 11, 2016, (http://www.whfoods.com/genpage.php?tname=nutrient $\& d b i d=128)$

37. The New York Times, Chloride in Diet, WWW Document, Accessed on October 11, 2016, (http://www.nytimes.com/health/guides/nutrition/chlorid e-in-diet/overview.html)
38. Institute for Vibrant Living, Is your scalp making you sick?, WWW Document, Accessed on October 11, 2016, (http://www.ivlproducts.com/Health-Library/HealthConcerns/Supplement-Vitamins-Wellness/ls-your-scalpmaking-you-sick/)

39. J. Axe, Top 10 Vitamin B5 Foods (Pantothenic Acid), WWW Document, Accessed on October 11, 2016, (https://draxe.com/top-10-vitamin-b5-foods-pantothenicacid/)

40. F. Watanabe, Exp. Biol. Med. 232 (10), 1266 (2007).

41. United States Department of Agriculture Agricultural Research Service, Basic Report:11450 Soybeans, green, raw, WWW Document, Accessed on October 11, 2016, (https://ndb.nal.usda.gov/ndb/foods/show/3162?fgcd=\& manu $=\&$ lfacet $=\&$ format $=\&$ count $=\& \max =50 \&$ offse $\% 20 \mathrm{t}=$ $\&$ sort=default $\&$ order=asc $\&$ qlookup=soybean $+\& d s$ )

42. United States Department of Agriculture Agricultural Research Service,11457, Spinach, raw, WWW Document, Accessed on October 11, 2016, (https://ndb.nal.usda.gov/ndb/foods/show/3167?manu=\& fgcd $=\& d s=)$

43. United States Department of AgricultureAgricultural Research Service, Basic Report: 11667, Seaweed, spirulina, dried, WWW Document, Accessed on October 11, 2016, (https://ndb.nal.usda.gov/ndb/foods/show/3306?manu=\& fgcd $=\& d s)$

44. United States Department of Agriculture Agricultural Research Service, Basic Report: 31019, Seaweed, Canadian Cultivated EMI-TSUNOMATA, dry, WWW Document, Accessed on October 11, 2016, (https://ndb.nal.usda.gov/ndb/foods/show/8216?fgcd=\& manu $=\&$ lfacet $=\&$ format $=\&$ count $=\& \max =50 \&$ offset $=\&$ sor $\mathrm{t}=$ default \&order=asc \& qlookup=Seaweed $\% 2 \mathrm{C}+$ Canadian + Cultivated+EMI-TSUNOMATA\%2C+dry\&ds)

45. United States Department of Agriculture Agricultural Research Service, Basic Report: 11239, Mushrooms, Chanterelle, raw, WWW Document, Accessed on October 11, 2016, (https://ndb.nal.usda.gov/ndb/foods/show/2989?manu=\& fgcd $=\& d s)$ 
46. United States Department of Agriculture Agricultural Research Service, 45026810, BOB'S RED MILL, RAW WHEAT GERM, UPC: 039978011503, WWW Document, Accessed on October 11, 2016, (https://ndb.nal.usda.gov/ndb/foods/show/28754?manu= $\& f g c d=\& d s$ )

47. United States Department of Agriculture Agricultural Research Service,16108, Soybeans, mature seeds, raw, WWW Document, Accessed October 11, 2016, https://ndb.nal.usda.gov/ndb/foods/show/4845?fgcd=\&m anu $=\&$ lfacet $=\&$ format $=\&$ count $=\& \max =50 \&$ offset $=\&$ sort $=$ default $\&$ order $=$ asc $\&$ qlookup=soybean $+\& d s=$ 
